\title{
Pola Hidup Sehat Dan Pemanfaatan Tanaman Obat Keluarga Untuk Mencegah Hipertensi Dan Diabetes Melitus
}

\author{
Yuningtyaswari ${ }^{1}$ Titiek Hidayati $^{2}$ \\ 1. Departemen Biologi sel dan histologi, Program Studi Kedokteran, Fakultas Kedokteran dan Ilmu Kesehatan, Universitas Muhammadiyah \\ Yogyakarta, Tamantirto, Kasihan, Bantul, Indonesia \\ 2 Departemen Epidemiologi, Kedokteran Keluarga dan Kesehatan Masyarakat, Program Studi Kedokteran, Fakultas Kedokteran dan IImu \\ Kesehatan, Universitas Muhammadiyah Yogyakarta, Tamantirto, Kasihan, Bantul, Indonesia \\ Email: hidayatifkumy@yahoo.co.id. \\ DOI: $10.18196 / p p m \cdot 39.126$
}

\begin{abstract}
Abstrak
Beberapa permasalahan kesehatan di Desa Bokoharjo sebagai desa tujuan wisata yaitu (i) masih tingginya angka kejadian penyakit degenerative seperti hipertensi, diabetes melitus, jantung coroner, dan strok akibat perilaku hidup tidak sehat Desa Bokoharjo, (ii) sudah ada pengrajin jamu hasil kerja BKKBN dalam bentuk UPPKS namun anggota UPPKS sebagian pengrajin jamu tersebut belum memiliki pengetahuan dan keterampilan dalam pencegahan penyakit degeneratif, (iii) Meskipun sudah terdapat paguyuban pengrajin jamu namun belum memiliki promotor kesehatan untuk penyadaran masyarakat terhadap penyakit degeneratif yang banyak dialami warga desa Bokoharjo dan tokoh masyarakat menyampaikan harapannya pada FKIK UMY untuk terlibat dalam peningkatan pengetahuan dan keterampilan masyarakat terutama para pengrajin jamu tntang pencegahan penyakit degeneratif, terutama hipertensi dan diabetes melitus. Berdasarkan permasalahan kelompok sasaran maka TIM PM PKM FKIK UMY membuat program promosi kesehatan bagi pengrajin jamu Bokoharjo tentang penyakit degeneratif. Berdasarkan permasalahan tersebut, tim PM FKIK UMY dan UAD melakukan serangkaian kegiatan PM untuk (i) membentuk tim promotor kesehatan RAJA PANDU BOGOSINI dari pengurus inti pengrajin jamu Desa Bokoharjo, (ii) meningkatkan pengetahuan dan keterampilan pengrajin jamu mengenai upaya pencegahan primer dan sekunder penyakit degeneratif hipertensi dan diabetes melitus dan (iii) melakukan training for trainer promotor kesehatan RAJA PANDU BOGOSINI sebagai promotor kesehatan dan pengembangan media promosi kesehatan. Program PM PKM ini dilakukan di Desa Bokoharjo, Pedukuhan Klurak, Prambanan, Sleman. Alih teknologi yang sudah dilakukan adalah alih teknologi kesehatan bidang promosi kesehatan yaitu metode berperilaku hidup sehat dengan pengenalan sejak dini faktor risiko dan upaya pencegahan primer dan sekunder hipertensi dan DM, pembuatan media audiovisual untuk promkes. dan cara penimbangan berat badan dan pengukuran tekanan darah. Luaran yang diharapkan dari program ini adalah : (1). kelompok promotor kesehatan RAJA PANDU BOGOSINI sebagai pioneer kampanye deteksi dini penyakit degeneratif, (2) (HKI modul dan Model pelatihan dan pendampingan kampanye deteksi dini dan pencegahan penyakit hipertensi dan DM,
\end{abstract}

Kata Kunci:hipertensi; diabetes melitus, TOGA, PHBS

\section{Pendahuluan}

Hasil Riset Kesehatan Dasar tahun 2010 melaporkan bahwa lebih dari separuh $(55,3 \%)$ penduduk Indonesia menggunakan jamu dan 95\%-nya menyatakan bahwa jamu bermanfaat (Balitbangkes, 2010). Salah satu manfaat jamu adalah sebagai pencegahan penyakit hipertensi dan diabetes melitus. Hipertensi dan diabetes melitus merupakan penyakit degeneratif dengan prevalensi tinggi di masyarakat.

Kondisi geografi dan klimatologi Desa Bokoharjo mendukung keberadaan berbagai jenis tanaman obat. Berbagai tanaman obat seperti sereh, pegagan, jahe, temulawak, kumis kucing, sukun, coklat, pare, mengkudu, sirsat dan kapulogo tumbuh dengan baik di Desa Bokoharjo, termasuk di Dukuh Klurak Baru. Kandungan flavonoid, polifenol, dan alkaloid bersifat antioksidatif dan imunomodulator, sehingga meningkatkan imunitas dan menghambat proses degeneratif. Antioksidan dan imunomodulator, adalah suatu aktivitas biologis yang dibutuhkan untuk pencegahan dan penghambatan progresivitas penyakit degeneratif seperti hipertensi dan diabetes melitus. Salah satu metode yang dapat dilakukan oleh masyarakat desa untuk mengisi lahan/pekarangan yang kosong dengan cara memfungsikannya sebagai apotek hidup dengan koleksi berbagai jenis tanaman obat yang dapat memberikan manfaat bagi keluarga untuk pengobatan berbagai penyait, termasuk penyakit hipertensi dan diabetes melitus, sekaligus 
fungsi penghijauan bagi lingkungan sekitarnya. Problematika lain yang dijumpai adalah pemanfaatan tanaman obat oleh masyarakat yang dirasa belum optimal dan masih sebatas pengalaman empiris tanpa disertai informasi ilmiah terkait khasiat, keamanan, dan pemanfaatan tanaman obat yang baik.

Setiap perilaku kesehatan dapat dilihat sebagai fungsi pengaruh kolektif dari pengetahuan, sikap, persepsi, sarana prasarana, dukungan sosial dan peraturan perundangan (Pratiwi, 2016). Pemanfaatan tanaman obat oleh masyarakat dirasa belum optimal dan masih sebatas pengalaman empiris tanpa disertai informasi ilmiah terkait khasiat, keamanan, dan cara pembuatan obat tradisional yang baik. Edukasi kepada masyarakat sangat diperlukan tentang bagaimana penggunaan obat tradisional secara tepat berdasarkan pendekatan ilmiah yang berbasis bukti (evidence-based). Kebutuhan edukasi kaitannya dengan evidence base dan pelatihan dapat meningkatkan keterampilan, pengetahuan serta sikap masyarakat dalam menggunakan tanaman obat secara tepat dan rasional. Penelitian ini bertujuan untuk untuk melakukan edukasi dan pelatihan mengenai pemanfaatan TOGA sehingga masyarakat memahami penggunaan TOGA secara tepat dan rasional. Berdasarkan permasalahan yang ada maka program pemberdayaan masyarakat yang dilakukan bertujuan meningkatkan kesadaran dan keterampilan dalam memanfaatkan TOGA sebagai upaya untuk pencegahan penyakit hipertensi dan diabetes melitus.

\section{Metode Pelaksanaan}

Pemberdayaan masyarakat ini dilaksanakan pada tahun 2020 di Dukuh Klurak Baru, Desa Bokoharjo. Pemberdayaan ini menggunakan pendekatan edukasi pada orang dewasa dan pendampingan. Program intervensi untuk pemberdayaan masyarakat ini telah mendapatkan izin dari pemerintah desa dan dikuatkan dengan adanya surat kesepakatan bersama dengan Kepala Dukuh. Tahapan kegiatan pemberdayaan masyarakat ini adalah sebagai berikut:

\section{Tahap Perencanaan dan Pengembangan Program}

Pada tahap perencanaan, tim mengidentifikasi masalah dan menetapkan prioritas masalah dengan melakukan observasi lapangan dan wawancara dengan tokoh masyarakat untuk mengetahui masalah dan prioritas masalah yang menjadi kebutuhan masyarakat. Berdasarkan kebutuhan dan prioritas masalah tersebut kemudian dikembangkan program pemberdayaan masyarakat sesuai dengan pendekatan sesuai kebiasaan di masyarakat. Adapun penjabaran dari rencana program pelatihan pemberdayaan masyarakat adalah sebagai berikut:

1. Rencana Penyelenggaraan Sosialisasi Program. Kegiatan sosialisasi dilakukan dalam bentuk penyuluhan tentang jenis dan manfaat TOGA

2. Pengembangan Rencana Pelaksanaan Pelatihan. Setiap pelatihan memiliki tujuan pembelajaran spesifik disertai dengan modul yang sesuai. Telah dikembangkan beberapa modul pelatihan untuk pelaksanaan program ini antara lain modul pemanfaatan TOGA sebagai pencegahan dan pengobatan pelengkap untuk hipertensi dan diabetes melitus, modul pembuatan sediaan minuman kesehatan dan modul perilaku hidup sehat untuk pencegahan hipertensi dan diabetes melitus. Selain itu, juga telah disusun modul untuk pelatihan sebagai promotor kesehatan (Kusumandari, 2016)..

\section{Tahap Pelaksanaan}

Telah dilakukan sosialisasi program tentang pemanfaatan pekarangan dengan penanaman tanaman obat keluarga, manfaat tanaman obat keluarga secara ekonomi dan kesehatan serta pentingnya berperilaku hidup bersih dan sehat untuk meningkat status kesehatan dan taraf kesejahteraan keluarga. Sosialisasi program dilakukan di aula samping masjid, pelatihan pembuatan minuman kesehatan, dilakukan dengan pendekatan cara pembelajaran 
orang dewasa. Satu program pelatihan direncanakan untuk satu target keterampilan. Program pemberdayaan. dilakukan selama 30 hari.

\section{Hasil dan Pembahasan}

Rencana program yang disusun pada fase persiapan dapat terlaksana sesuai jadwal yang sudah ditetapkan. Uraian pelaksanaan program pelatihan pembuatan minuman kesehatan dan perilaku hidup sehat berdasarkan nilai kearifan lokal masyarakat Dukuh Klurak Baru, Bokoharjo. Jenis kegiatan sosialisasi dan pelaksanaan promosi kesehatan terdiri atas:

1. Edukasi dan promosi kesehatan tentang pengenalan faktor risiko hipertensi dan diabetes melitus serta gaya hidup sehat untuk mengatasi faktor risiko kegemukan, kurang aktivitas dan merokok. Materi yang dikemas dengan bahasa ringan sesuai dengan bahasa orang awam menarik perhatian para peserta. Sebagian besar peserta merasa mendapatkan manfaat atas kegiatan ini.,

2. Edukasi dan promosi kesehatan tentang pengenalan komplikasi dan akibat hipertensi dan diabetes melitus serta upaya untuk mencegah kejadian komplikasi. Perubahan perilaku hidup menyesuaikan tujuan terapi memegang peran penting pada upaya pencegahan kejadian komplikasi dan berkembangnya penyakit hipertensi dan DM (diabetes melitus) menjadi strok, gagal ginjal, dan penyakit gagal jantung. Pengenalan diet rendah garam, diet rendah kalori, makanan berserat dan contoh gerakan dan aktivitas fisik telah dirasakan manfaatnya sebagai upaya untuk meningkatkan keberhasilan terapi dan pencegahan kejadian komplikasi pada hipertensi dan DM.

3.

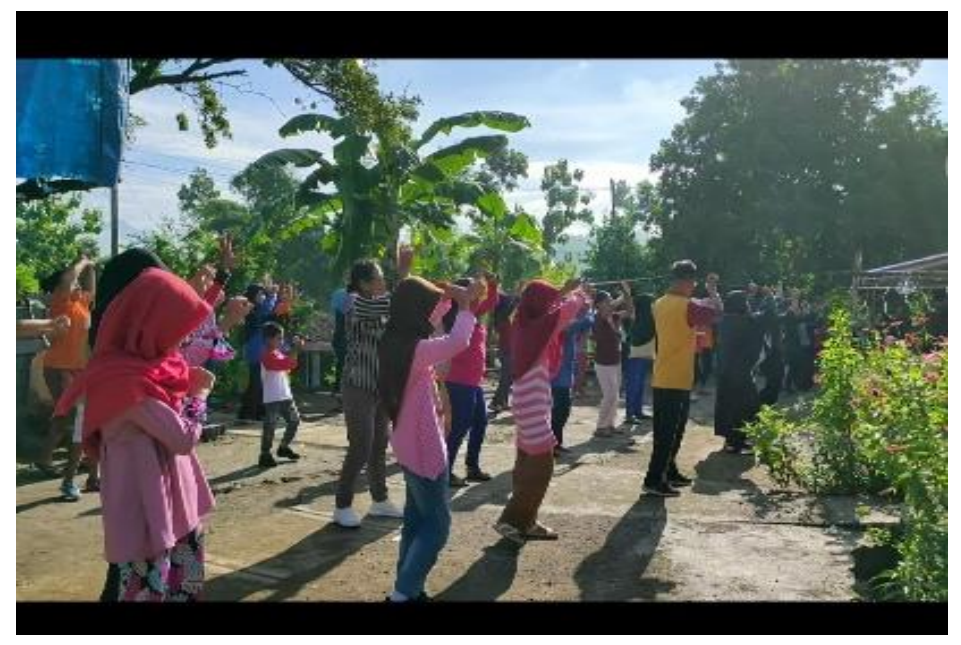

Gambar 1. Latihan fisik bersama dalam bentuk senam kebugaran. Latihan fisik atau senam terbukti mampu meningkatkan keberhasilan terapi pada pasien DM dan hipertensi.

4. Penyuluhan tentang cara jitu pemanfataan pekarangan rumah sebagai apotek hidup, jenis dan kegunaan TOGA untuk pencegahan hipertensi dan diabetes melitus di keluarga. Telah dijelaskan beberapa jenis tanaman obat keluarga dan manfaatnya sebagai pencegah penyakit hipertensi dan diabetes melitus keluarga. Hasil dari kegiatan ini adalah terjadi peningkatan pengetahuan masyarakat mulai usia anak sampai dewasa di Desa Bokoharjo tentang manfaat dan kegunaan kelor, pegagan, jahe, sereh dan coklat untuk pemeliharaan kesehatan dan pencegahan penyakit hipertensi dan diabetes melitus. Tingkat pemahaman peserta penyuluhan sekitar $80 \%$

5. Pelatihan pembuatan minuman kesehatan untuk pencegahan komplikasi hipertensi dan diabetes melitus. Hasil dari kegiatan ini adalah masyarakat kelompok sasaran memiliki pengetahuan dan keterampilan cara pembuatan minuman kesehatan berbahan tanaman 
obat keluarga (pegagan, kelor, meniran, coklat dan daun sukun) untuk pencegahan kejadian komplikasi gagal ginjal, strok atau gagal jantung pada penderita DM dan hipertensi. Pada akhir kegiatan pelatihan pembuatan minuman kesehatan (teh kesehatan) dilanjutkan dengan penyerahan seperangkat alat untuk pembuatan teh dan ekstraksi (Gambar 2).

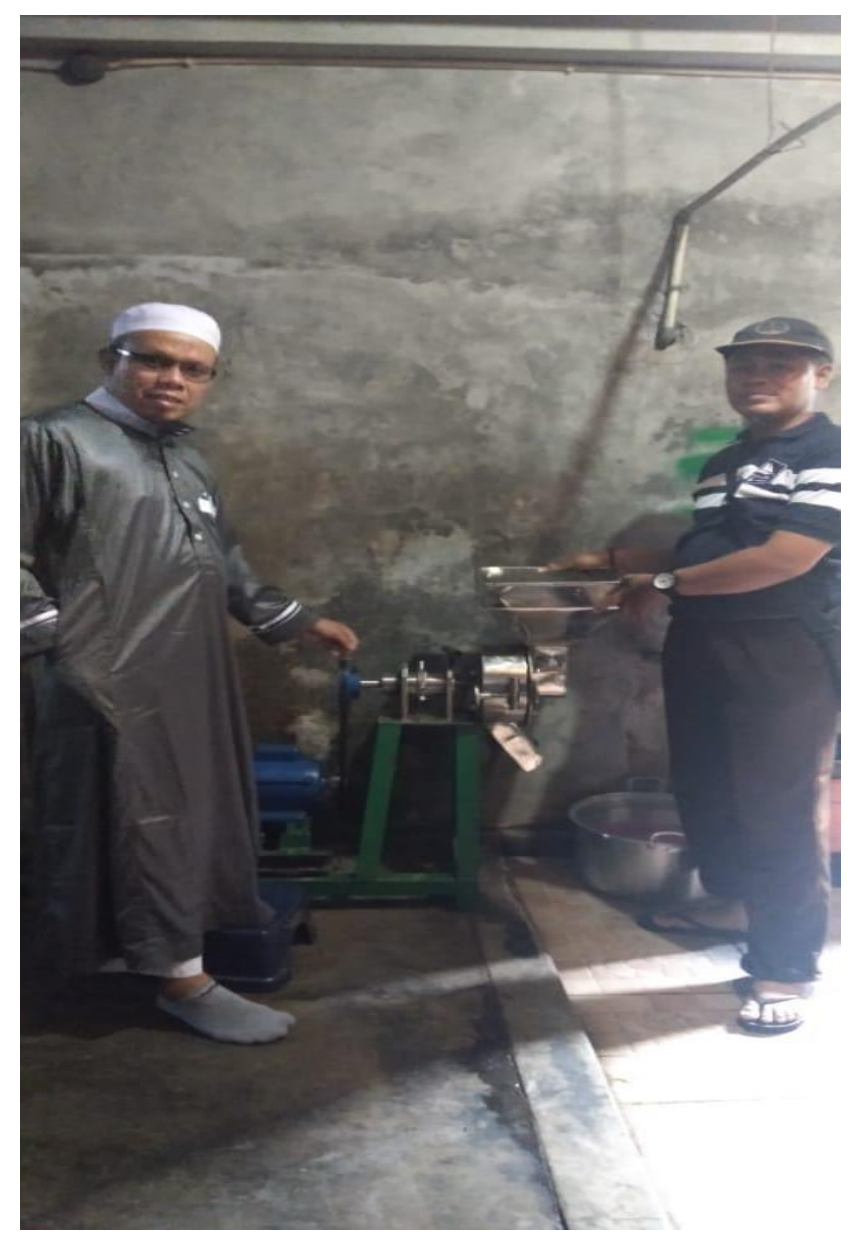

Gambar 2. Proses penyerahan alat ekstraksi dan pembuatan teh kesehatan kepada salah satu pengrajin jamu di Desa Bokoharjo.

Di daerah sasaran telah tumbuh berbagai TOGA dengan manfaat sebagai pencegahan hipertensi dan DM. beberapa tanaman tersebut adalah meniran, pegagan, temulawak, jati, sukun, coklat dan kelor. Beberapa kegiatan sosialisasi penyakit degeneratif (DM, hipertensi), perilaku hidup sehat, manfaat TOGA dan minuman kesehatan dilakukan pada semua kelompok masyarakat dari balita, anak, remaja, dewasa hingga lansia. Materi atau isi dan metode edukasi disesuaikan dengan dengan kelompok sasaran (Abu Talib et al., 2018).

Tabel 1. Riwayat sakit terdahulu yang dialami oleh penduduk Bokohardjo tempat PKM

\begin{tabular}{lrr}
\hline Jenis penyakit pada penduduk & Frekuensi & prosentase \\
\hline Alergi dingin & 2 & 2.6 \\
DM & 1 & 1.3 \\
Hipertensi & 10 & 13 \\
ISK batu ginjal & 3 & 4 \\
Malaria & 1 & 1.3 \\
\hline
\end{tabular}




\begin{tabular}{lcc}
\hline Prostat & 1 & 1.3 \\
Infeksi empedu & 1 & 1.3 \\
Rematik dan Sakit pinggang & 2 & 2.6 \\
Tidak sakit & 54 & 72 \\
& 75 & \\
\hline
\end{tabular}

Masyarakat Bokoharjo sudah memiliki beberapa komunitas olah raga dan aktivitas sosial. Menanamkan gaya hidup sehat dan pemanfaatan TOGA perlu dilakukan sejak dini terutama untuk pencegahan penyakit degeneratif Sutardi, 2017). Promosi kesehatan ternyata dapat meningkatkan kesadaran berperilaku hidup sehat dan mendorong masyarakat meningkatkan aktivitas fisik efektif menurunkan komplikasi hipertensi dan DM di daerah Bokohardjo.

\section{Simpulan}

Program promosi kesehatan meningkatkan pengetahuan dan keterampilan masyarakat mengenai faktor risiko dan cara pencegahan hipertensi dan DM. Edukasi dan pelatihan pemanfaatan tanaman obat keluarga sebagai minuman kesehatan untuk pencegahan komplikasi strok, gagal ginjal dan gagal jantung pada pada penderita hipertensi dan DM meningkatkan pemahaman sebesar $80 \%$.

\section{Ucapan Terima Kasih}

Ucapan terima kasih dan penghargaan yang sebesar-besarnya diberikan kepada PPM UMY kepada pemberi dana dengan nomor kontrak PPM 031/PEN-LP3M/I/2020, Kepala Dukuh Kluwar Baru, Takmir masjid, Desa Bokohardjo Krakalan dan seluruh aparat pemerintah desa yang telah memberikan fasilitas dan dukungannya selama kegiatan pengabdian dilaksanakan.

\section{Daftar Pustaka}

Abu Talib, I. F. et al. (2018) 'Community Empowerment through Rehabilitation and Reconstruction in Social Sector of Kuala Krai, Kelantan, Malaysia', Procedia Engineering. Elsevier B.V., 212(2017), pp. 294-301. doi: 10.1016/j.proeng.2018.01.038. American Diabetes Association [ADA]. (2017). Diagnosis and Classification of

Diabetes Melitus. Diabetes Care. Jan; 34(Suppl 1): S62-S69, doi: 10.2337/dc11-S062 ,PMCID: PMC3006051.

Codario, R. A. 2011. Type 2 Diabetes, Pre Diabetes, and The Metablic Syndrome. USA : Humana Press.

Fa, D. et al. (2012) 'Faktor Determinan Risiko Osteoporosis Di Tiga Provinsi Di Indonesia', Media of Health Research and Development, 20(2 Jun), pp. 91-99. doi: 10.22435/mpk.v20i2Jun.787.

Fatimah Noor R., 2015, Diabetes Melitus Tipe II (review artikle), Lampung: Fakultas Kedokoteran Universitas Lampung.

Kemenkes RI. (2014). PROFIL KESEHATAN INDONESIA. Jakarta: Kementrian Kesehatan Republik Indonesia.

Muthoharoh Ainun, 2017, Pengaruh Konseling Farmasis dan Pesan Motivatif Terhadap Perubahan Perilaku dan Kualitas Hidup Pasien Diabetis Melitus Komplikasi Hipertensi Rawat Jalan Poliklinik Penyakit Dalam Di RSUD Panembahan Senopati, Bantul (thesis), Universitas Ahmad Dahlan, Yogyakarta.

Mansjoer, A., dkk. 2005. Kapita Selekta Kedokteran. Jakarta: Media Aesculapius. 


$$
1852
$$

Palaian, Subish \& Prabhu, Mukhyaprana \& Shankar, P Ravi,2006, Patient counseling by pharmacist - A focus on chronic illness. Pakistan journal of pharmaceutical sciences. 19. 65-72.

Rantucci, M.J. 2007.Komunikasi Apoteker-Pasien: Panduan Konseling Pasien(Edisi 2). Penerjemah : A.N. Sani. Jakarta: Penerbit Buku Kedokteran EGC .

Sammulia Suci F, Fita Rahmwati, Tri Murti Andayani, 2016, Perbandingan Pill Box Dan Mediaction Chart Dalam Meningkatkan Kepatuhan Dan Outcome Klinik Geratri Di Kota Batam, Fakultas Farmasi, Universitas Gadjah Mada, Yogyakarta.

Smeltzer, S. C., \& Bare, B. G. 2001. Buku Ajar Keperawatan Medikal-Bedah Brunner dan Suddarth Volume 2, Edisi 8. Terjemahan oleh Agung Waluyo, dkk. Jakarta: EGC.

Trihono, Partini P et al. (2018) Kidney Disease Profiles Among Adolescents In Indonesia, Acta Med Indones-Indones $J$ Intern Med $\bullet$. 